\title{
Katharina Nieswandt Anscombe on the Sources of Normativity
}

\begin{abstract}
Anscombe is usually seen as a critic of "Modern Moral Philosophy." I attempt a systematic reconstruction and a defense of Anscombe's positive theory.

Anscombe's metaethics is a hybrid of social constructivism and Aristotelian naturalism. Her three main claims are the following: (1) We cannot trace all duties back to one moral principle; there is more than one source of normativity. (2) Whether I have a certain duty will often be determined by the social practices of my community. For instance, duties imposed by other people's rights are socially constructed. (3) Whether something constitutes a good, however, will often be determined by human nature-which is not socially constructed.
\end{abstract}

\section{Key Words}

Deontic Modals $\bullet$ Aristotelian Necessities $\bullet$ Hume's Circle $\bullet$ Promises $\bullet$ Practices $\bullet$ Rights

\section{Publication \& Download}

The Journal of Value Inquiry, forthcoming. http:/ /ink.springer.com/article/10.1007/s10790-016-9562-9

\section{Acknowledgements}

I am deeply grateful to Ulf Hlobil and Michael Thompson, who both commented on at least a dozen versions of this paper. Without these intense discussions, I would never have been able to put together the many fascinating pieces of Anscombe's thought. I furthermore profited much from the comments of the editor-in-chief, John Hacker-Wright, and from an anonymous reviewer. I thank Stanford University's McCoy Family Center for Ethics in Society for funding my research during this time.

Final Draft, May 2016 
[T] here are, of course, a great many things whose existence does depend on human linguistic practice. The dependence is in many cases an unproblematic and trivial fact. But in others it is not trivial - it touches the nerve of great philosophical problems. The cases I have in mind are three: namely rules, rights and promises. ${ }^{1}$

\section{Introduction}

Currently, Elizabeth Anscombe's account of first-personal knowledge and her theory of action attract much attention. Other aspects of her extensive work remain mostly unknown. One such hidden treasure is her metaethics. The main reason why this has gone unnoticed, I believe, is that Anscombe never set it out in a systematic fashion. I reconstruct Anscombe's theory from her various writings, and I put it in a contemporary context. I hope to make a strong case for her theory. Even readers who will find that they do not agree with Anscombe, however, might still be interested in the puzzles that she raises.

Section 2 will set out these puzzles. Section 3 presents Anscombe's solution and discusses its advantages over seemingly similar proposals (viz. rule-consequentialism, contractarianism and Rawls' contractualism). Section 4 summarizes Anscombe's theory. Section 5 then argues that Anscombe's theory allows us to combine attractive features of realism and anti-realism.

\section{Many Moral Justifications Are Circular}

The starting point for Anscombe's theory is the following observation: Rules, rights and promises are self-referential, and they are so in two ways: (1) Their content "is given in a formula for acting whose meaning it is that one must act in accordance with it," i.e., with this formula; and (2) in those cases where there truly is a justification to act in accordance with such a formula, that justification indeed is the formula itself. ${ }^{2}$ So rules, rights and promises prescribe actions; they purport to themselves be the justification of these prescriptions, and they indeed are the justification if there is one. (For presumably not all rules, rights and promises are binding.)

\subsection{The Self-Referentiality of Promises}

This self-referentiality is most obvious for promises. To give a promise is to give a sign by which one creates a duty for oneself. That sign can be an explicit utterance, such as "I promise to $\varphi$;" but it might just as well consists in, for instance, a nod at the right moment or in writing one's signature in a certain place. The meaning of the sign is 
that through the sign itself being given, a duty is created. Juliet nods at the right moment (for instance after Romeo has asked whether she'll pick up the kids tomorrow); the meaning of this nod is 'I hereby-by nodding - create a duty for myself to pick up the kids tomorrow'; and under usual circumstances the nod indeed creates that duty.

Anscombe illustrates the peculiar self-referentiality of the promise-sign as follows: Imagine, your nervous system were connected to a paralyzing device. That device makes it impossible for you to $\varphi$ after you have said "Let there hereby be a constraint upon me [not to $\varphi$ ]." 3 Such a sign-the "Let there..." utterance-would be much easier to understand than our actual promises are. The utterance activates the device, and then the device brings about the constraint. The utterance does not create the constraint simply by being uttered. Just as the sentence "I hereby open you," said while staring hard at a door, does not, simply by being uttered, open that door. ${ }^{4}$ In the case of "I hereby promise you to $\varphi$," on the other hand, it really is hereby-by the utterance- that an obligation to $\varphi$ is created (if it is). That last "hereby" refers to that through which promises go beyond "predictions and expressions of intention." 5 The "significance of a promise is that it not only of itself (that is without a mechanism) but by its significance purports to make it the case that there is a new obligation."

Anscombe's observation, to which I shall frequently return below, thus is that promises are self-referential in two ways: (1) The "hereby" that one might use in the explicit formulation of a promise refers to the promise itself. (2) If the duty that the promise purports to create is indeed created, then it is created through that to which the "hereby" refers, viz. the promise itself.

\subsection{Hume's Circle}

Anscombe claims that David Hume already discovered this self-referentiality of promises. The respective passages became famous as "Hume's Circle." them "rather cryptic." 8 But for Anscombe, Hume hit on a profound problem in metaethics here. She formulates Hume's Circle as follows:

$[\mathrm{A}][\ldots]$ promise contains (perhaps on the face of it just is) a future-tense description which the giver then makes come true-or he breaks the promise. The obligation is a kind of necessity to make the description come true. But what sort of necessity is that?

We may say: the necessity is one of making the description come true-or being guilty of something. Of what? Of breaking a promise. [...] Not just to go on running round in the circle let's try again and say: of an injustice, a wrong against the one whom the sign, the description, was given. But what wrong was that? The wrong of breaking a promise ... We are back in the circle after all. [...]. Let's have a sign for [...][something being a promise], say "I promise," put in front of the prediction. Or, because we know that too well, let's invent one: "I blip." It's not the prediction 
by itself that it's an offence not to make come true, it's the 'blipping' of it, or its being a blip. And what is the meaning of its being a blip? That it's an offence not to make the attached description come true. But what offence? The offence of going contrary to a blip. It seems clear that we just haven't explained what blipping is at all. ${ }^{9}$

That is Hume's Circle "translated into philosophically neutral terms," that is, in a formulation that does not require us to subscribe to Hume's moral philosophy and his philosophy of mind. ${ }^{10}$ A promise is a sign that purports to oblige us to act in a certain way and that (at least usually) does oblige us. (1) It purports to oblige us by being what it is: a promise. (2) And if we ask for the mechanism by which it could possibly oblige us, then the answer again is: by being what it is, a promise. Thus, promises are selfreferential in two ways: Any definition of the concept 'promise' will have to mention promises again, as will any justification for why promises (can) bind us.

One might fail to notice that there are two problems, because a promise signifies the creation or willing of an obligation. It might be thought that if you could show how there can be a sign with that signification, you would be home and dry: the obligation is generated by the giving of a sign which has that signification! Hume's clarity of mind perceived that this is not so. [...] I might say "Let there be a constraint upon me to do such-and-such." This is a sign signifying a will to be constrained. It is clear that we could understand this, and still go on to ask: "Will there be any such constraint?"11

The first problem concerns the meaning of utterances such as "Let there be a constraint upon me...," the second concerns their mechanism. If we were to define Anscombe's concept 'blip', we'd have to say that a blip is a thing that claims of itself to oblige us. And if we were then pressed to say why blips (at least usually) oblige us, then the answer would again be that they are blips: Blips can give us reason to comply with them. ${ }^{12}$

Notice that we cannot escape Hume's Circle by filling the terms "injustice," "wrong" or "offence" with more content. ${ }^{13}$ Suppose, we think that what's wrong with a wrong action is that it does not aim to maximize the greatest good of the greatest number. So we also think that breaches of promise are actions that do not aim to maximize the greatest good of the greatest number. Even so, we would have to specify bow a breach of promise is a way of doing this. You must, because you blipped it.And what does that mean, "I blipped it"?-That it's an offence not to make the attached description come true.-But what offence? How do I fail to aim at the greatest good of the greatest number in going contrary to my blip? Had I just expressed an intention to carry out the action in question or predicted that I would, then I would not act against the greatest good of the greatest number simply by going contrary to my announcement. (Unless, of course, we imagine other special circumstances.) That 
is, had I just announced instead of promised the action, then there would be no moral issue. Our problem is that we are unable to specify how we wrong others if we blip our announcement and then don't do as announced. That problem cannot be solved through a more detailed explanation of what a wrong in general is. We need to know what makes this particular kind of action wrong.

For the same reason, Anscombe would not be satisfied with explanations of promising like that by Thomas Scanlon. ${ }^{14}$ Anscombe might grant that Scanlon's version of the Rawlsian "Principle of Fidelity" is extensionally correct in the following sense: ${ }^{15}$ In all cases where someone blips, the conditions specified by Principle F are fulfilled. First of all, however, she would doubt whether the reverse is true, i.e., that in all cases where the conditions specified by Principle F are fulfilled, someone blips. ${ }^{16}$ Juliet, CEO of a company, could (1) voluntarily and intentionally create an expectation in the shareholders that her company will expand, (2) knowing that the shareholders want to be assured of this and (3) behaving in a way that creates this assurance etc. What she did might nevertheless not amount to a blip. More importantly, however, Principle F does not tell us what the harm is in not making good on one's blips. How do we wrong others in disappointing their expectations if these expectations were created by a blip? Notice that considerations about whether or not Principle F is "reasonable" do not help at this point. We want to know what makes Principle F a reasonable principle.

\subsection{The Self-Referentiality of Rules}

For Anscombe, Hume's discovery has a much broader application than he realized. It applies to rules and rights as well, and hence has huge implications for metaethics. This is how she applies his discovery to rules:

The parallel between rules and promises is obscured by the fact that a promise is a sign [...]. [...] The requirement of acting so because of a rule is not generated by the rule's being uttered. Nevertheless the problem is parallel; for the necessity is supposed to be generated by the existence of the rule, and in explaining what a rule is beyond a mere regularity, one will say, for example, that it is given in a formula for acting, whose meaning is that one must act in accordance with it. ${ }^{17}$

The parallel to promises is more obvious if you imagine the rule to be stated on a sign. ${ }^{18}$ Traffic signs, for instances, state rules_-even if they only show a picture. 


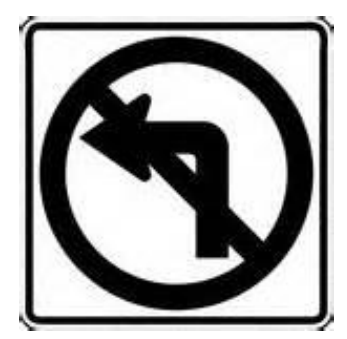

Figure 1: Implicitly self-refential sign

The content of this sign is not "a mere regularity," such as 'People prefer not to turn left here'. The sign says: "Follow me-and don't turn left." In general terms, the content of a rule according to which you must $\varphi$ is that it itself obliges you to $\varphi .^{19}$ In fact, all rules are like the following sign:

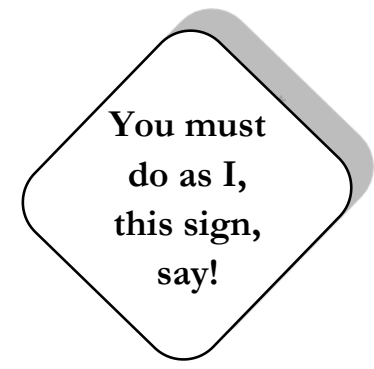

Figure 2: Explicitly self-referential sign

If we were to formulate the traffic rule depicted above, then we would probably say: "You must not turn left here." That formulation appears not to contain a reference to the rule itself and thus covers up the parallel with promises. The justification for why you must not turn left, however, is that this rule itself says that you must not. The correct way to understand "must not" in "You must not turn left here" hence is as 'you must not because I, this rule, say so'.

\subsection{The Self-Referentiality of Rights}

Although Anscombe claims that Hume's discovery applies to rights, too, she does not explain how-apart from a few, very condensed remarks. ${ }^{20}$ I suggest that we extrapolate as follows: Rights are similar to rules and unlike promises, in that we generally do not create a right through formulating it. (A lawgiver might be able to do that, of course.) In explaining what a right is, however, beyond a mere prompt or tradition, one can again say "that it is given in a formula for acting, whose meaning is that one must act in accordance with it." According to this formula, the right-holder may do or does not have to do something; certain others must or may not do something else; and that is because of the right itself. If Romeo has a right to his wage, for instance, then this right is something that goes beyond him prompting his employer to give him money, 
and it goes beyond his employer traditionally giving him money. It means that his employer must give him money and must do so because of this, Romeo's right, itself.

The parallel between rights and promises is even harder to discern than that between rights and rules. Many formulations that we give of rights do not mention any action at all_-just take "Romeo has a right to his wage" or "This money is Romeo's." Moreover, the actions that a right regulates are often not actions of the rightholder but actions of others concerning the right-holder. (In our example, they are actions of Romeo's employer.) Thereby, formulations of rights often cover up the fact (1) that rights prescribe actions and (2) that they claim of themselves to be the justifications for these actions. That, I suggest, is how Anscombe's ideas can be applied to the case of rights.

\subsection{A Special Class of Deontic Modals}

Anscombe believes that formulae which express rules, rights or promises belong to (or perhaps form) a special class of deontic modal claims: Their 'justification' does not supply an independent fact that grounds the supposed obligation. It only classifies it as being an obligation of the rule-type, the right-type or the promise-type.

In expressing rules, rights and promises, we use claims that mark an action as either necessary or possible. For each affirmative claim, such as "You must ...," "You can ..." or "You may ...," there is a negative correlative, such as "You don't have to ...," "You cannot ..." or "You must not ..." We often combine these modals with what appears to be a justification. The prohibition "You can't sit there," for instance, might be combined with: "This is N's place." 21 The resulting claim "You can't sit there; this is N's place" appears to have the same logical structure as, for instance: "You can't move that; the shelf will fall down."22 The meaning of "The shelf will fall down," however, can be explained without reference to "You can't move that;" whereas Hume's Circle shows us that such is not possible for the meaning of "This is N's place." If this place is N's, then this means (among other things and under usual circumstances) that others are not allowed to sit there. N's right is not an independently describable fact that could serve to ground the prohibition. The prohibition partly constitutes N's right.

Anscombe introduces a special terminology for deontic modal claims that only allow for combinations with such a dependent 'justification'. She calls such a claim "forcing modal" in case it is affirmative and "stopping modal" in case it is prohibitive. ${ }^{23}$ Forcing and stopping modals express a necessity that is neither a logical nor a physical necessity - which is why Hume called the forcing and stopping modals associated with a promise "not intelligible naturally." 24 Quae deontic necessity claims, forcing and stopping modals are compatible with the falsity of the claim embedded under them; that is, they do not obey the "Axiom T." 25 Anscombe illustrates the idea of a stopping modal as follows: "If I say 'You can't wear that!' and it's not, for example, that you are too fat to get it on, that's what I call a stopping modal."26 The necessity that such 
modals express is of its own kind; it is the necessity to act in accordance with the prescription because of the prescription.

Anscombe also introduces a term for the dependent reason that can accompany a stopping or forcing modal. She calls these dependent reasons "logoi."

[For] it is a 'reason' in the sense of a logos, a thought. But if we ask what the thought is, and for what it is a reason, we'll find that we can't explain them separately. We can't explain the "You can't" on its own; in any independent sense it is simply not true that he can't (unless 'they' physically stop him). But neither does "it's N's ..." have its peculiar sense independent of the relation to "you can't". Of course, once these linguistic practices exist, we can detach the two parts from one another and "it's N's" can appear as an independent reason, for example a reason why one will not do something. ${ }^{27}$

Instead of "logos," Anscombe says, "I might also use 'theme' [...] for the second half of 'you can't... because...,' where the two halves are not independent." 28 For what the second half effectively does is to classify the preceding modal as being of a particular type. Rules, rights and promises are three such "general logos-type[s]." Each of them "is an abstraction from many particular cases; a label which tells you the formal character of the stopping modal." ${ }^{29}$ About the logos-type 'right', for instance, Anscombe says:

I have located the generation of the concept right in a certain kind of use of a stopping modal with what appears to be a reason attached: the reason says that something is N's, or is 'of N,' or 'for N'. [...] We have here a very special use of the name of a person, or a very special way of relating something to a person, which explains (not is explained by) the general term "right." [...] The general term "right" is constructed because, as it were, our language feels the need for it. As, for example, the general term "relation" was invented. ${ }^{30}$

\section{Practices as a Solution to Hume's Circle}

We said that rules, rights and promises pose two problems: Neither can we define what they are, without bringing them in again; nor can we justify the duties they potentially impose through anything but themselves. Hume's own solution to this twofold circle is that "promises have no force antecedent to human conventions." 11 Anscombe aspires to formulate a more generalized version of this, "which fully justifies Hume in his own solution." 32 She calls a "practice" what Hume has called a "convention," and she argues that practices are what gives (1) rules, rights and promises their special content as well as (2) their power to bind us. The resulting moral theory 
is a hybrid of social constructivism and Aristotelian naturalism. It distinguishes two fairly independent spheres of justification: Practice-internal necessity is socially produced. The practice itself is necessitated by human nature.

Some practice views rightfully incurred much criticism. ${ }^{33}$ Anscombe's view is a practice conception, but as I shall show below, it is not vulnerable to the main objection levelled against rule-consequentialism, contractarianism and Rawls's view (see Sect. 3.4).

\subsection{Practice-Internal or "Conventional" Necessity}

We were unable to define what a rule, a right or a promise are, but "definition is not the only mode of explanation." 34 We can say more about them and about how they bind us, even though this explanation cannot take the form of "Rules, rights and promises make it necessary for you to do something by [insert independent fact here]." Unfortunately, Anscombe herself is not very explicit about how the concept of a practice sheds light on that of a rule, of a right and of a promise. What I shall say in the current section will hence go far in terms of interpretation. I read her argument (and Hume's) as an argument by exclusion.

I shall start with the necessity created by rules in a game. For game rules, no one doubts that the necessity they impose requires the game. Take that rule of chess which obliges Juliet to move her king, who is in check. The content of this rule is 'Players must move their king if he's in check because of me, this rule'. That is, we are in Hume's Circle. At the same time, the situation is not very mysterious: The rule is part of a larger set of rules that together form the game of chess. The necessity that the rule generates exists within that game. Were Juliet not playing chess, then it would not be necessary for her to move this particular piece of wood. ${ }^{35}$ In fact, that piece of wood would not even be a king, nor would there be the situation of 'being in check'. ${ }^{36}$

How, then, does a game generate a necessity for its players? Some would suggest that this necessity rests on a kind of contract: Through agreeing to play chess, Juliet implicitly agreed to follow the rules of chess. Hence her duty to follow any of these rules ultimately is the duty to keep this implicit agreement. That suggestion, though, is unhelpful: It already presupposes the concept of a promise which is among those that Anscombe set out to investigate and definitions of which got caught in Hume's Circle. Others will suggest that Juliet's chess-duties stems from her opponent Romeo's expectations, which she may not violate. (That would be to suggest a Principle F for games.) Juliet's duty, however, is independent of Romeo's expectations: If Romeo is not well-informed about the rules of chess, he might expect Juliet to move a different piece. Nevertheless, Juliet would still have the duty to move her king. It is the game itself that requires her to move the king, not the other player's expectations.

Both these suggestions attempt to break Hume's Circle. They are akin to the paralyzing device imagined in Section 2.1: The external fact that there is a contract or an expectation grounds the duty. Contrary to that, Anscombe does not understand 
the relation between a game and a rule-based duty as a grounding-relation. The rule is not something external to the game, which the game endows with force. For her, the concepts 'rule' and 'game' are interdependent. (A definition of what chess is, for instance, could consist in a complete list of the rules of chess.) We pick up these concepts as a package, so to speak, early on in our lives, when we learn to participate in games.

Consider the learner in chess or some other game. Of course: "You have to move your king, he's in check" is equivalent to "The rules of the game require that, in this position, you move your king." But a learner may not yet have this idea: the rules of the game require... Accepting it when told "You have to move your king, he's in check," is part of learning that very concept: 'the rules of the game require'. Requiring is putting some sort of necessity on you, and what can that be? All these things hang together at some early stage: learning a game, learning the very idea of such a game, acquiring the concept of 'you have to' which appears in the others' speech, grasping the idea of a rule. Nor is there a distinct meaning for "being a rule of the game" (unless the general idea has been learned from other games) which can be used to explain the "you have to" that comes into that learning. ${ }^{37}$

We can hence not ground the necessity created by a rule in its game. Nevertheless, the notion of a game can shed some light on this necessity. A game is one of these social patterns, in which we learned to participate, when we were "trained in the practices of reason." 38 The notion of a game does not help us to a "definition" or a "translation or analysis" of 'rule'. ${ }^{39}$ The game-situation, however, is very familiar to us: In a certain social setting, others do things that function as prompts for us to do things and vice versa. Those who don't show the trained reaction are 'wrong'. Anscombe thinks that this dependence between a rule and a game is also the correct way to think of promises and to think of rights. Those, too, exist in the context of a bigger social practice.

It may be asked: "But what is this necessity [created by a promise]?" The answer is given only by describing the procedure, the language-game, which as far as concerns the 'necessity' expressed in it does not differ from this one: "I say 'ping' and you have to say 'pong.", 40

As intimated, I understand Anscombe's argument as an argument by exclusion. (1) It is logically possible for us to act against rules, rights or promises, and (2) it is physically possible for us to do so. In all cases where "you are told that you 'can't' do something" because of a rule, a right or a promise, "you plainly can, as comes out in the fact you sometimes $d 0 . "{ }^{\prime \prime}$ In what sense, then, is it impossible for us to act against them? (3) In Section 2.2, we tried to argue that it is normatively impossible for us to act against rules, 
rights or promises, that we wrong others if we do. We were, however, unable to specify what is wrong with doing that. How then do rules, rights and promises generate a necessity? What option is left? (4) Anscombe thinks that we cannot give any definition of this necessity. Our education, however, has given us a practical understanding of it: It is the necessity that exists within certain social patterns, in which we have learned to move early on. The wrong that you commit in disrespecting a rule, a right or a promise is that of not reacting as trained to a prompt within such a pattern. Anscombe seems to think that a description of the practice is the only explanation that is left and the furthest we can go. She does not coin a name for this type of necessity; so let me introduce the name "conventional necessity" for it.

Qua argument by exclusion, what has been said does not prove that rules, rights and promises can only exist and can only have force as part of practices. ${ }^{42}$ Anscombe, however, makes a very convincing case: (i) She shows the semantic similarity of all three entities: All three are self-referential deontic modals. (ii) The understanding she suggests seems commonsensical for rules. (iii) Her account sheds some light on all three entities, despite the fact that Hume's Circle makes it impossible to define them.

Anscombe's result may appear disappointingly quietist. As we shall see in Section 3.3, however, it is quite powerful: It will enable us to formulate a criterion for what one actually ought to do-faced with other people's real or supposed rights.

\subsection{Practice-External or "Aristotelian" Necessity}

We saw that Anscombe regards the necessity that rules, rights and promises create as socially created. So far, her moral philosophy sounds rather relativistic: We must follow certain prescriptions because our community agreed on these. How could that ever give us a theory that justifies substantial moral duties?

Contrary to individual right-based, rule-based or promise-based duties, practices can be justified through something other than conventions on Anscombe's account. In several of her discussions, she quotes Aristotle's 'dictionary', according to which "one sense of 'necessary' is: 'that without which some good will not be attained or some evil avoided'."43 Philippa Foot later named this type of necessity "Aristotelian necessity." Aristotelian necessity is a metaphysical necessity: In all possible worlds in which the good in question is attained/the evil avoided in an adequate way, suchand-such is the case. For Anscombe, practices are among the things that can be necessary in this Aristotelian sense. We could summarize her account thus: The justification of a rule-based, a right-based or a promise-based duty appeals to what is right, in the sense of a correct move within the practice. The justification of a practice appeals to what is good - in the sense of good for human beings.

First, it can be necessary for a community to adopt a new or to keep an existing practice. Anscombe claims, for example, that it is necessary for human beings to have the practice of promising; because it is often necessary for us to get each other to do something and because that practice is often the only means of doing so. 
What ways are there of getting human beings to do things? [...] [F]ew people have authority over everyone they need to get to do things, and few people either have power to hurt or help others without damage to themselves or command affection from others to such an extent as to be able to get them to do the things they need others to do. [...] [In default of these means, promising] is at least $a$ means of getting people to do things. Now getting one another to do things [...] is a necessity for human life, and that far beyond what could be secured by those other means. ${ }^{45}$

Second, it can be necessary for a practice to have a particular shape. A practice serves some function, and sometimes it will be unable to do so unless it contains this-or-that rule or assigns this-or-that right. In that case, the rule or the right, too, is necessary in Aristotle's sense-not just the complete practice. Anscombe gives the following example:

[T] hose who have and carry out the task of bringing up children quite generally perform a necessary task. It cannot be done without children's obedience. So those people have a right to such obedience. ${ }^{46}$

Anscombe might or might not be correct about this and the previous examples, but we only need to evaluate the structure of her arguments here. The following detail is very important: In deciding whether a certain rule or a certain right must be part of a practice, we are considering the rule or the right as a type, as opposed to the rule that a given individual must follow in a given situation or the right of a given individual in a given situation. Thus, the reason why adults with children have a right to tell these children what to do (if they have such a right) is that raising children would otherwise be impossible. But the reason why mother $\mathrm{M}$ has a right to tell this child $\mathrm{C}$ what to do is that $C$ is her child. Or, to pick up our earlier example of occupying N's seat: The reason why people in such-and-such a situation have an exclusive right to use suchand-such objects (if they have such a right) could be that refusal of that right would make it impossible for our practice of private property to serve its function. The reason why $N$ has a right to that seat, however, is that $\mathrm{N}$ bought the ticket. So a general right can be necessary in the Aristotelian sense, while the duty to respect an instantiation of a right always is a practice-internal or "conventional" necessity.

Naturally, it need not be a new rule or a new right, which is necessary in Aristotle's sense, but it can also be the modification of an existing rule or an existing right or its complete abolishment.

[Arguments for such a modification][...] might be about the ill consequences of including such-and-such types of people in the general rule, or about the inner meaning of the rule (like the 'intent' of a statute) understanding of which will make us 'see' that these people don't fall under it. Or [...][they] may attack the whole rule root and branch as doing nothing but harm or as 'senseless'. "Why should mere ... mean that one can ...; 
that equally or more valuable people should have to yield place in ...?" Thus the qualification referred to in the logos may be rhetorically belittled; the disadvantages to those not so qualified rhetorically enlarged upon. ${ }^{47}$

In discussing Aristotelian necessity, Anscombe only considers two cases: (1) the justification of individual practices and (2) the fit of a right or a rule with its practice. It seems, though, that there are a number of other cases to which similar considerations should apply: (3) the fit between different practices, (4) between the rules of different practices and (5) between the rules of one practice and the function of another practice. All of these are potential sources of conflict. The most plausible interpretation, I suggest, is a holistic picture of Aristotelian necessities: Some practices (and their rules) are necessary only if you hold all other practices fixed. Others are necessary even if you allow the other practices to vary. Between these two extremes there are degrees of robustness of necessity.

Aristotelian necessity derives from goods. Anscombe has a naturalist view of the latter: ${ }^{48}$ She thinks that for human beings, as for all living beings, there is a specieswide standard of flourishing. ${ }^{49}$ Certain things are necessary to reach that standard. Therefore these things constitute goods for human beings. Some human goods can only or best be realized with the help of certain practices, and this is the justification for having the respective practices and for why these practices must contain certain rules or assign certain rights. Given that human goods are determined by human nature, it is irrelevant whether a given community recognizes them as goods or not.

[Aristotelian necessity] gives us a way of arguing for a right without appeal to custom, law or contract; and similarly of arguing that some customary right is no right but is, rather, a customary wrong. If something is necessary, if it is for example a necessary task in human life, then a right arises in those whose task it is, to have what belongs to the performance of the task. [...] Justification by necessity (of a goal, and of the means to it) is one of the most common - and most commonly abused-forms of justification offered. [...] The 'necessity' of the goal is very likely the suspicious term of the argument. But in form it is sound enough $[\ldots] .{ }^{50}$

Notice that Anscombe's Aristotelian stance on goods is logically independent of her distinction between two kinds of necessity. In principle, one could combine a nonAristotelian theory of goods with her metaethical theory of rules, rights and promises. Examples would be more hedonistic or more pluralistic theories of goods. Naturally, not all of these logically possible hybrids would also make for plausible moral theories. (I shall say more about this in Section 3.4 below.) 


\subsection{How to Connect the Right with the Good?}

In Sections 3.1 and 3.2, I extracted two central components of Anscombe's metaethics from her various papers. The current section will put these together and draw out some implications. In the remainder of the paper, I shall then place the reconstructed theory among current alternatives.

We saw that Anscombe distinguishes two sorts of necessity. First, there is practice-internal or "conventional" necessity. The necessity imposed by a rule, a right or a promise is of that kind.

(CN) It is conventionally necessary for $\mathrm{N}$ to do A if: a certain practice P exists in N's community and $\mathrm{P}$ allows someone to use " $\mathrm{N}$ must do A" as a forcing modal.

Second, there is practice-external or "Aristotelian" necessity:

(AN) It is Aristotelianally necessary for a community $\mathrm{C}$ to have a practice $\mathrm{P}$ and for $\mathrm{P}$ to contain rule $\mathrm{R}$ if: an important good $\mathrm{G}$ will otherwise not be realized (or a grave evil $\mathrm{E}$ not be prevented) in an adequate way.

This definition of Aristotelian necessity is simplified. As mentioned in Section 3.2, a holistic view of practices seems most plausible: Whether we should actually adopt a practice $\mathrm{P}$ will also depend on its interaction with various other factors, such as already existing practices. What counts as "adequate," too, will partly depend on these others practices. Even with complete information about these other factors, however, I do not expect that an exact definition could be given. (In that respect, the concept of adequate means is similar to the concept of usual circumstances, of which Anscombe says that its meaning "can only be indicated roughly, by giving examples of exceptional circumstances in which A would not hold." $)^{51}$

Anscombe stays mostly silent about the relation between these two types of necessity. We would need to know how the right and the good connect, however, in order to decide what anyone actually ought to do. The following four inferences regarding Anscombe's view seem warranted.

First, Anscombe must allow some influence of Aristotelian necessity on our conventional duties. For if she does not, then we end up with the implausible position of the radical cultural relativist, according to whom practice-internal necessities must always be respected-which Anscombe explicitly rejects. ${ }^{52}$

Second, Anscombe cannot allow that there is a rule-based, a right-based or a promised-based duty to adopt a new or to modify an existing practice (unless that duty is part of another, already existing practice). To give an example: The members of a government cannot be under a duty to introduce the practice of democratic elections because those whom they rule have a right to democratically elect their government 
(unless those ruled have such a right as part of another, already existing practice-as when their government is under the jurisdiction of a court, for example, that rules that they must hold elections). It could be, however, that there is an Aristotelian necessity to have the practice of democratic elections. Claiming that would require us to show that an important good cannot adequately be realized without that particular form of governance.

Third, Anscombe has to reject the idea that the influence of Aristotelian necessity on our conventional duties is such that Aristotelian necessities 'back up' conventional duties (that is, that practice-external necessity backs-up practice-internal necessity). She thus has to reject rule-consequentialism (such as defined by Hooker) as well as theories that ground rules, rights and promises in the advantages of a social contract (an example would be Gauthier's contractarianism) or theories that debunk them as successful evolutionary devices (an example would be Binmore's theory). ${ }^{53}$ All of these theories would justify our above-mentioned, individual duty not to take a certain seat by arguing that the practice of private property results in better long-term consequences than a lack of it. ${ }^{54}$ They thus use the justification for the overall practice as a justification for any individual move within that practice, too. In other words, they collapse the justification of individual duties into the justification of the practice. All three types of theories treat practice-internal justifications as an intermediate step: Ultimately, it is the justification of the practice which justifies the practice-internal duty. Various objections have been raised against rule-consequentialist and contractarian justifications of individual duties. I shall discuss the most important objection in the next section. For the moment, I only want to stress that Anscombe must reject this whole family of justifications: They give an external justification for our duty to respect rules, rights or promises - viz. the maximization of good consequences (either for yourself or for all). They thus claim that it is possible to leave Hume's Circle, which Anscombe rejects. ${ }^{55}$ Hence a back-up relation between Aristotelian and conventional necessity cannot be the kind of connection that she has in mind.

Fourth, Anscombe would have to reject solutions such as Michael Thompson's "transfer principle." 56 Thompson treats practices as similar to life forms and practiceinternal actions as similar to individual living beings. Consequently, he regards the goodness of the individual action as determined by the practice: Good practice-internal actions are non-deficient instantiations of the respective practice; goodness 'transfers' from the level of the practice to the level of the individual action. "The essence of the matter is that the special form of account or cause or non-accidentality that is associated with a life-form or a practice reaches all the way to the individual operations that instance the thing. [...][T] hat through which we understand any one of a person's many practice-instancing acts of fidelity is precisely that through which we understand any other act of fidelity performed by him, or indeed by any other agent; [...] it might be formulated in a description of the practice. [...][T] here is no room to distinguish what Gauthier praised under the title of a disposition from what Rawls praised under 
the name of a practice." 57 Thompson suggests "that we take the disposition of fidelity - the 'ultimate source' and 'inner basis' of a faithful person's many acts of fidelityto be simply identical with the larger practice of promising." ${ }^{58}$ Anscombe would presumably reject this equation of practices with dispositions. The disposition of fidelity, for instance, can show up in many different actions, only some of which are practiceinternal actions and hence happen within a two-level structure. (Thus, one can hold that helping a friend in a tight corner shows the disposition of fidelity, without having to hold that friendship is a practice.) Anscombe should be even more opposed, however, to the suggested analogy between practices and life forms. For one thing, she believes that practices have a telos, whereas life forms presumably don't. ${ }^{59}$ Practices can also be better or worse, which is not the case for life forms. Most importantly, however, the telos of the practice differs from the telos of the individual, practiceinternal action. This means that the practice and the practice-internal action must have different standards of goodness. While Anscombe would agree that one cannot identify something as, for instance, the breaking of a promise unless one has the concept of the practice of promising and that there can be no such action as breaking a promise unless there is a practice of promising (also see fn. 36 above), she must deny that the standard for evaluating the practice of promising helps us in evaluating individual actions within that practice. Hume's Circle rules out the very idea of a normative transfer principle.

Anscombe does not explicitly tell us how to connect the right with the good. I shall advance a new suggestion here, which uses ideas from "On Brute Facts," one of her papers on social ontology. In that paper, Anscombe argues that certain institutions form the necessary background of certain facts, in the sense that some facts could not exist if the respective institution did not exist. As she points out, however, such a metaphysical dependence of a fact on its background does not entail that a description of this fact must (or even may) mention the background. One of Anscombe's examples is: "[T]he statement that I owe the grocer does not contain a description of our institutions, any more than the statement that I gave someone a shilling contains a description of the institution of money and of the currency of this country. On the other hand, it requires these or very similar institutions as a background [...]." ${ }^{\prime 00} \mathrm{Sim}$ ilarly, I should argue that the existence of certain duties - viz. those imposed by rules, rights and promises - requires the good purpose of the practice as a background. That, however, does not entail that a justification of these duties must (or even may) mention the practice. My suggestion is to regard the necessity of the practice as a precondition of any practice-internal duty. $\mathrm{N}$ can only have a right that we vacate that particular seat if the whole practice of private property indeed serves some good or prevents some evil. Saying that, however, does not entail that our duty toward N may be justified by drawing on the necessity of the practice of private property. (The latter justification is one that attempts to break Hume's Circle.) If we regard the necessity 
of the practice as a background, we instead arrive at the following prima facie necessity claim:

(PFN) It is prima facie necessary for $\mathrm{N}$ to do A if: a certain practice $\mathrm{P}$ exists in N's community $\mathrm{C}$ and $\mathrm{P}$ allows someone to use " $\mathrm{N}$ must do $\mathrm{A}$ " as a forcing modal-provided that it is Aristotelianally necessary for $\mathrm{C}$ to have $\mathrm{P}$.

In other words, it is necessary to respect a conventional necessity if the practice within which that conventional necessity exists is necessary in Aristotle's sense. Suppose, for example, that the marriage practice of a given community is such that it systematically harms one party to the marriage by expropriating them. Prima facie, there would be no necessity for any given member to obey the rules of that practice. It seems to actually hinder a good life instead of furthering it.

We could formulate the difference between rule-consequentialism and contractarianism on the one hand, and the view that I attribute to Anscombe on the other, as follows:

(R.-Consequ. \& Contract.) If there is a conventional necessity for $\mathrm{N}$ to do $\mathrm{A}$ and honoring this conventional necessity will have the best long-term consequences, then it is prima facie necessary for $\mathrm{N}$ to do A because of A's better long-term consequences.

(Anscombe's view)

If there is a conventional necessity for $\mathrm{N}$ to do $\mathrm{A}$ and there is an Aristotelian necessity for N's community to have the associated practice, then it is prima facie necessary for $\mathrm{N}$ to do A because of the conventional necessity for $\mathrm{N}$ to do $\mathrm{A}$.

According to the rule-consequentialist/contractarian view, the source of the individual duty are the consequences of the practice. According to Anscombe's view, the source is my promise, your right or the rule. The lesson that Anscombe draws from Hume's Circle is that we cannot specify an independent justification for the duties generated by a rule, a right or a promise. We can only classify them as that type of duty, and the best way to understand duties of that type is as existing as part of a practice. That practice must indeed be justified in order for us to be under a normative (as opposed to a mere social) necessity to honor the respective duties. The practice, however, does not justify these duties. The duties are a matter of convention.

Some might wonder why I am speaking of a "prima facie necessity" as opposed to an "all things considered necessity" here. This is because PFN does actually not prescribe a duty all things considered. It prescribes a duty certain-conventional-and- 
certain-Aristotelian-necessities considered. There are, however, many other circumstances that influence what any real person in a given situation ought to do. I already mentioned that a plausible Anscombean theory would be holistic. That is, $\mathrm{N}$ would have to consider other practices and their rules, in order to form an all-out judgment. There is more, though. One further thing that any all-out judgment about an action must take into account are certain empirical facts. Perhaps Romeo's employer has a right against him that he operate a certain machine-but not if that machine is malfunctioning and hence dangerous. A third thing to consider for an all-out judgment are emergencies and other special situations. Thus, it is necessary for Plato to restore his friend's weapon if a justified practice of private property exists in Athens and allows the friend to use "You must give me that weapon" as a forcing modal against Platobut not if the friend is in a state of madness and hence likely to bring about evil. ${ }^{61}$ Presumably this list is not exhaustive. We can imagine different ways of including these and other circumstances in an Anscombean conception: Perhaps the practice of private property is trumped by something more important in the last example; perhaps it contains an emergency clause. Such open details, however, do not need to worry us at this point, where the aim is to set out the main features of Anscombe's view. I suggest that the described background-foreground construction is a plausible way to connect her ideas.

\subsection{Anscombe Bypasses the Main Objection against Practice Views}

Rule-consequentialist and contractarian justifications of individual, practice-internal duties have met with a variety of objections. ${ }^{62}$ This has led many to regard practice views as a failed project. The probably most influential objection says that practice views give the wrong reasons for individual duties. It simply seems false, for instance, that Juliet must do what she promised Romeo to do because sticking to her announcement will bring about better consequences for Verona (or for humanity or all sentient beings) in the long run. For a start, that justification has the odd implication that it would really be all citizens of Verona and not Romeo in particular who would be wronged if Juliet broke her promise. A similar objection has been made against Rawls' contractualist practice view. ${ }^{63}$ Thus, Scanlon argues that, on Rawls' account, Juliet's duty is "a general obligation to the members of the group who have contributed to and benefit from the practice" of promising. ${ }^{64}$ In his famous paper "Two Concepts of Rules," Rawls warns us against collapsing the two levels, but his own "principle of fairness" seems to incur a parallel problem. Rawls justifies practice-internal duties through a general requirement to comply with the rules of justified practices the benefits of which one has voluntarily accepted: "[T]n making a promise, that is, in saying the words 'I promise to do X' in the appropriate circumstances," Juliet "knowingly invokes the rule and accepts the benefits of a just arrangement." Her resulting duty to keep that promise "is a consequence of the principle of fairness." ${ }^{66}$ Because the principle of fairness says "that a person is required to do his part as defined by the 
rules of an institution when two conditions are met: first, the institution [...] satisfies the two principles of justice; and second, one has voluntarily accepted the benefits of the arrangement." Juliet thus has a duty to do as promised because she voluntarily participated in the fair practice of promising. She is one of the beneficiaries of that practice; hence fairness commands her to also do her share. The most natural way to understand Juliet's duty therefore is in the way that Scanlon does, viz. as a duty toward all of those other participants in the practice who actually do contribute their fair share. To break a promise is to free-ride.

Anscombe fully agrees with this criticism of many existing two-level views. For her, Hume's Circle demonstrates that it is the fact that Juliet has promised which creates Juliet's duty — not the goods to be realized through the practice of promising, nor any other external reason, such as Rawls' general duty to play fair. Within the practice of promising, Juliet must do such-and-such (viz. carry out an action that she announced in a special way), and the reason is that Juliet promised (that is, that she announced the action in that special way). From Anscombe's perspective, we could say that the objection by Scanlon and others points out an implication of Hume's Circle: The only correct justification of the promise can be that promise itself. Those who draw on the usefulness of the practice in order to justify moves within the practice, or on general facts about fairness, try to give a justification that Hume has demonstrated cannot exist. ${ }^{67}$

Couldn't other practice views adopt Anscombe's construction and thus circumvent the "wrong reason objection"? They presumably could and perhaps should adopt it. Thus, we could imagine a 'second-level consequentialism', which justifies practices through their good consequences, but which regards practice-internal duties as a matter of stopping/forcing modals and logoi. This new kind of consequentialism would be very similar to (Anscombean) virtue ethics, except for its conception of the relevant goods: Instead of Hooker's "Collapse of Virtue Ethics," we would see the reverse. ${ }^{68}$ Disputes between this new view and Anscombe's view would boil down to disputes about the correct conception of goods. We would have to look at these new theories in detail, though, in order to determine how plausible they are and whether they actually preserve enough of their original spirit to still count as consequentialist, contractarian or contractualist.

\section{Summary and Implications of Anscombe's Metaethics}

The account reconstructed here from Anscombe's various papers combines social constructivism and Aristotelian naturalism: (1) Duties imposed by a rule, a right or a promise are conventional duties. This means that they exist as part of a practice and 
that their justification must appeal to features internal to that practice. Practice-internal justifications are circular. (2) The justification of a practice, on the other hand, must appeal to practice-external considerations-Anscombe suggests that practices must be justified through human needs. A practice-external justification through human needs is not circular. (3) A conventional duty can only be justified if it is part of a justified practice. In other words, the goodness of a practice is a precondition for an individual agent's duty to comply with a conventional duty assigned within that practice. Anscombe thus opposes rule-consequentialism and contractarianism, according to which the goodness of a practice ultimately justifies the individual agent's duty. (As specified under point 1 , conventional duties must be justified by practice-internal considerations on Anscombe's account.)

The following two implications of this account seem most important: First, what is right cannot be directly inferred from what is good. If Anscombe is correct, then the good only forms the background of the right. Second, we should reject moral theories that derive all individual duties from a single source-such as a general duty to further the greatest good of the greatest number or to treat everyone as an end in themselves. Any duty that can be described as the duty to respect a certain rule, a right or a promise must be justified within a given practice. Juliet's duty to respect N's right to seat $\mathrm{S}$ therefore has a different source than her duty to do what she promised to Romeo. On Anscombe's account, there are at least as many sources of individual duties as there are necessary practices.

\section{Advantages of Anscombe's Metaethics}

I mostly argued for Anscombe's account from its own merits. As a last step, let me point out some advantages that it has over alternative in metaethics. We already saw that it avoids the usual problems of practice views (see Sect. 3.4). I believe that it furthermore combines elements of moral realism and moral anti-realism in such a way as to offer us the best of both worlds.

A long-standing objection against non-naturalist moral realism says that the latter entirely disconnects moral entities from the empirical world: Neither can these entities be part of causal chains, which poses metaphysical problems, nor can they be systematically investigated, which poses epistemic problems. ${ }^{69}$ Aristotelian naturalism is a non-reductivist alternative to these views. Instead of reducing moral to non-moral or even to physical facts, it claims that what human beings are determines how we should live. Now, one can take various perspectives on human beings: We are physical objects, organisms, political animals, self-conscious creatures, and so forth-Anscombe would certainly include spiritual beings, too. ${ }^{70}$ Within Aristotelian naturalism, the diverse aspects of human nature are not claimed to be reducible; hence this paradigm can permit diverse ways of investigating human goods. Not just the natural but also the social sciences and the humanities might provide insights here, and we might even 
include ways of understanding that lie outside of the realm of science altogether, such as faith or art. ${ }^{71}$ Of course, many will take issue with one or another of these modes of understanding and their objects. Still, within Aristotelian realism, we have epistemic access to moral entities and these can be causally relevant, without the premise that moral facts are reducible to non-moral ones.

The anti-realist component of Anscombe's view, too, possesses an advantage over most alternatives. Most varieties of social constructivism and expressivism are varieties of moral relativism. ${ }^{72}$ While their proponents welcome this feature, most other people (in- and outside of philosophy) tend to start worrying, when elementary rights and duties are declared to be social constructs or even a matter of personal attitudes. Anscombe's hybrid theory, too, regards rights as socially constructed. For her, however, rights are constructed within the boundaries of non-constructed goods.

Anscombe indeed has to reject natural rights à la Locke. ${ }^{73}$ For her, the idea of rights that exist before any practice exists is akin to the idea that the check-rule could exist before chess exists. She does, however, allow for universal rights in the following sense: If a certain human good can only be achieved through a practice that contains right $\mathrm{R}$, then it is necessary for any community to assign right $\mathrm{R}$ - whether they recognize that or not. With this conception, Anscombe might, in fact, have given us a much more powerful tool than Locke did. Locke supplies us with a list of rights, but he leaves it unclear what qualifies any right to be on that list (with the exception of property rights) and also how far the list could be extended. ${ }^{74}$ Anscombe supplies us with a basis on which to argue about what qualifies as a universal right.

Interestingly, we in fact often argue from human goods when pressed to justify human rights. Here is an example: The UNESCO's official justification for a universal right to a basic education says that "[e]ducation is a powerful tool by which economically and socially marginalized adults and children can lift themselves out of poverty and participate fully as citizens." 75 In other words, without education, certain goods (such as participation) cannot be achieved and certain evils (viz. poverty) not be prevented, the possession or prevention of which is a necessary part of any good human life.

Naturally, current realists and anti-realists believe that they can avoid the discussed objections (see footnotes 69 and 72), or they reject these objections. I hence do not expect to convince anyone who is already firmly based within an existing paradigm. For all those dissatisfied with the current selection, however, Anscombe might offer an alternative.

\section{Notes}

1. Elizabeth Anscombe, QLI, p. 118. My abbreviations of Anscombe's titles will follow Roger Teichmann, The Philosophy of Elizabeth Anscombe (Oxford: Oxford 
University Press, 2008), pp. ix-x: QLI—“On the Question of Linguistic Idealism;” RRP_-"Rules, Rights and Promises;" SAS_ “On the Source of the Authority of the State;" RP__"The Reality of the Past;" PJ_-"On Promising and its Justice and Whether it Need be Respected in foro interno;" BF_-"On Brute Facts." All page references are to Anscombe's Collected Papers (all volumes by Blackwell, Oxford 1981).

2. QLI, p. 120.

3. RRP, p. 98, emphasis original.

4. See RRP, p. 99.

5. RRP, p. 99.

6. RRP, p. 99, emphases original.

7. See David Hume, A Treatise of Human Nature: Being An Attempt to Introduce the Experimental Method of Reasoning into Moral Subjects. Ed. by Lewis A. Selby-Bigge. 2nd, rev. edition by Peter H. Nidditch (Oxford: Clarendon Press, 1978), Sections 3.2.1 and 3.2.5.

8. Rachel Cohon, "Hume's Moral Philosophy," in The Stanford Encyclopedia of Philosophy, ed. by Edward N. Zalta. (http://plato.stanford.edu/entries/hume-moral/, edition 2010), Sect. 10.1.

9. RRP, pp. 99-100, emphases original.

10. RRP, p. 100.

11. RRP, p. 98, emphases original.

12. Some of Anscombe's own descriptions of Hume's first problem are rather misleading. Passages like the one just cited, where she asks "how there can be a sign with that signification," might suggest that (1) the problem concerns the signal by which we promise, not the very concept 'promise' itself, or that (2) the problem does not concern the concept, but how such a concept can have evolved.

13. Anscombe does not discuss this suggestion.

14. See Thomas Scanlon, "Promises and Practices," Philosophy and Public Affairs, Vol. 19, No. 3 (1990), p. 208.

15. See John Rawls, A Theory of Justice. Revised Edition (Cambridge, Mass.: Belknap Press, 1999), Sect. 52, \10.

16. See Scanlon, op. cit., p. 210.

17. QLI, p. 120, emphases added.

18. RRP, p. 102.

19. A very wide notion of a rule could include entities for which the above claim is not true. It could, for instance, include instrumental rules, such as "In order for eggs to become soft, you must cook them for three minutes." Those so-called rules, however, actually formulate causal relations.

20. See SAS, p. 140.

21. See RRP, p. 101.

22. RRP, p. 101. 
23. Teichmann, op. cit., p. 97, introduces a third term, "permitting modal," for the negation of a stopping modal. ("May," for instances, could be defined as the negation of "can't".)

24. Hume, Treatise, Sect. 3.2.5, \2.

25. See RRP, p. 100.

26. RRP, p. 100.

27. RRP, p. 101, emphases original.

28. RRP, p. 102.

29. RRP, p. 102, emphasis added.

30. SAS, p. 142.

31. Hume, Treatise, Section 3.2.5, \6.

32. RRP, p. 100.

33. See, e.g., Scanlon, op. cit., or Abraham I. Melden, Rights and Persons (Berkeley: University of California Press, 1977), ch. 2.

34. SAS, p. 138.

35. Unless, of course, some non-chess-related fact made that necessary. (Perhaps Juliet needs to stick this piece of wood under the table, to keep that table from wobbling.)

36. John Rawls, “Two Concepts of Rules," Philosophical Review, Vol. 64, No. 1 (1955), p. 25, already points out that one cannot "steal a base" outside of baseball. John R. Searle, Speech Acts: An Essay in the Philosophy of Language (London: Cambridge University Press, 1969), Sect. 2.5, later called rules like the check-rule "constitutive rules."

37. RRP, p. 102, emphases original.

38. RRP, p. 103.

39. SAS, p. 138, and RP, p. 116, respectively.

40. PJ, p. 18, emphasis original.

41. RRP, p. 101, emphases original.

42. Michael Thompson, 'You and I: Some Puzzles about 'Mutual Recognition'," Manuscript (2012), Slides 23-48, suggests that such a proof might be constructed from an epistemological observation of Anscombe's in "On Promising..." (p. 10): I promise only if I understand myself to be promising. Hence, any complete definition of 'promise' would have to mention this self-understanding. That, however, makes it impossible to define 'promise', as well as to specify what a person who promises thinks she is doing. Anscombe, after bringing up this paradox, proceeds to give a description of the practice of promising (PJ, pp. 14-16), and she indeed claims that this description resolves the paradox (PJ, p. 17). It remains unclear, however, how exactly a practice enables us to think thoughts with such a selfreferential content. ("On Promising..." is Anscombe's earliest treatment of Hume's Circle, and her later papers do not mention the epistemic paradox anymore.) 
43. E.g. in RRP, p. 100. The original is to be found in Aristotle, Metaphysics, 1015a2223.

44. Philippa Foot, Natural Goodness (Oxford: Oxford University Press, 2003), p. 15.

45. PJ, p. 18, emphasis original.

46. SAS, p. 145.

47. SAS, p. 144.

48. Therefore, Anscombe's view differs fundamentally from the "Aristotelian constructivism" recently proposed by Mark LeBar in The Value of Living Well (Oxford; New York: Oxford University Press, 2013), Ch. 5.

49. Foot, op. cit., develops a more detailed theory of this standard. See furthermore Peter T. Geach, The Virtues. The Stanton Lectures 1973-74 (Cambridge: Cambridge University Press, 1979), and Rosalind Hursthouse, On Virtue Ethics (Oxford: Oxford University Press 2001).

50. SAS, p. 145, emphasis original.

51. BF, p. 24, emphasis added.

52. See SAS, pp. 142 and 145.

53. See Brad Hooker, Ideal Code, Real World: A Rule-Consequentialist Theory of Morality (New York: Clarendon Press, 2000), pp. 32-33; David Gauthier, Morals by Agreement (New York: Clarendon Press, 1986); Kenneth G. Binmore, Natural Justice (New York: Oxford University Press, 2005), Ch. 6.

54. Some of these theories favor egoism, some favor altruism. The consequences that count as relevant vary accordingly: Either they are the consequences that the agent suffers or they are the consequences that the group suffers. If the latter, then the relevant measure is either the aggregate of the consequences for all members of the group or it is the distribution of these consequences.

55. Hume's own conclusions from his discovery seem difficult to reconcile. On the one hand, he justifies the individual's duty to comply with the rules of a practice by the point of that practice, just as rule-consequentialists and contractarians do (see Treatise, Sect. 3.2.2). On the other hand, he realizes that there is no way to convince a "sensible knave," who "observes the general rule and takes advantage of all the exceptions" (An Enquiry Concerning the Principles of Morals, in Lewis A. Selby-Bigge \& Peter H. Nidditch, eds., David Hume's Enquiries. Reprinted from the Posthumous Edition of 1777 (Oxford: Clarendon, 1975), Sect. 9.2, SS 9-10).

56. Michael Thompson, "Practical Generality," in Life and Action: Elementary Structures of Practice and Practical Thought (Cambridge, Mass.: Harvard University Press, 2008), p. 167.

57. Thompson, op. cit., p. 209.

58. Thompson, op. cit., p. 208.

59. Friedrich Nietzsche would disagree for the human life form, which he describes as "a rope, tied between animal and super-human" (Thus Spoke Zarathustra, Introduction $\int 4$, my translation). 
60. BF, p. 22.

61. See Plato, Republic, 331c.

62. William Vitek, Promising (Philadelphia: Temple University Press, 1993), pp. 118-143 and 215-133, provides an overview of these criticisms. The contemporary heirs of practice views are theories that regard compliance with certain moral principles as constitutive of agency, such as Christine M. Korsgaard, Self-Constitution: Agency, Identity, and Integrity. The John Locke Lectures 2002 (New York, Oxford: Oxford University Press, 2009), or David Velleman, The Possibility of Practical Reason (New York: Oxford University Press, 2000). Criticisms of this kind of constructivism echo the earlier objection of Hume's sensible knave-such as David Enoch, “Agency, Shmagency: Why Normativity Won't Come from What Is Constitutive of Action," Philosophical Review, Vol. 115, No. 2 (2006).

63. See Rawls, A Theory of Justice, Sections 18 and 52.

64. Scalon, op. cit., p. 221. See also Niko Kolodny \& Jay Wallace (2003): "Promises and Practices Revisited," Philosophy \& Public Affairs, Vol. 31, No. 2 (2003), p. 122.

65. Rawls, A Theory of Justice, Sect. 18, \5.

66. Ibid., Sect. 52, \6.

67. For a detailed treatment of how Anscombe's own practice view differs from ruleconsequentialist, contractarian and contractualist views, please see my manuscript "Practice Views Revisited."

68. Brad Hooker, “The Collapse of Virtue Ethics," Utilitas, Vol. 14, No. 1 (2002).

69. The critics here rely on what came to be called the "Open Question Argument"see George E. Moore, Principia Ethica. Revised Edition with the "Preface to the Second Edition" and Other Papers, ed. by Thomas Baldwin (Cambridge: Cambridge University Press, 1993), pp. 62-69. For a solution to this problem within the non-naturalist realist paradigm, see Russ Shafer-Landau, Moral Realism: A Defence (Oxford, New York: Clarendon Press, 2005), Part 2.

70. It is difficult to determine what role Anscombe's religious commitments play for her conception of human nature. On the one hand, she regards the spiritual aspect as central. Thus, she says in "Contraception and Chastity": "What people are for is [...], like guided missiles, to home in on God, God who is the one truth it is infinitely worth knowing [...]" (in Mary Geach \& Luke Gormally, eds., Faith in a Hard Ground: Essays on Religion, Philosophy and Ethics (Exeter; Charlottesville, Va.: Imprint Academic, 2008), p. 172). In her work, however, Anscombe explicitly separates papers "written for the general public, for ordinary philosophical meetings or for philosophical journals" from papers that "were composed to express an explicitly Catholic view" and that "assume a certain background of common belief and faith" ("Introduction" to Collected Papers, Vol. III, p. ix). She here seems to follow the Thomist tradition of separating truths that can be recognized through natural reason from truths that have to be revealed. All of Anscombe's abovediscussed papers were written for philosophy audiences. 
71. Theodor Adorno's Aesthetic Theory is an example of such an epistemological conception of art. Following Adorno, a true work of art "mimics" empirical objects in such a way as to display their true nature (Ästhetische Theorie, ed. by Rolf Tiedemann (Frankfurt a. M.: Suhrkamp-Verlag 1970), see, e.g., pp. 14-16). The epistemic access that artworks provide differs in kind from the access provided by empirical investigations or theoretical analyses, and it cannot be substituted for either (see ibid., pp. 341-70).

72. Some expressivists, however, oppose relativism and argue that their theory avoids it. Examples are Simon Blackburn, "Quasi-Realism Is No Fictionalism," in Mark E. Kalderon, ed., Fictionalism in Metaphysics (New York: Clarendon Press, 2005), or Terrence Horgan \& Mark Timmons, "Expressivism, Yes! Relativism, No!" in Russ Shafer-Landau, ed., Oxford Studies in Metaethics, Vol. I (New York: Clarendon Press, 2006).

73. See John Locke, An Essay Concerning the True Original Extent and End of Civil Government, Chapters 1-5.

74. Many contemporary theories attempt to bridge this Lockean gap with a transcendental argument. James Griffin, On Human Rights (Oxford; New York: Oxford University Press, 2008), Ch. 2, for instance, argues that a right is a human right if it is a prerequisite for the possibility of agency.

75. UNESCO, The Right to Education (<http://www.unesco.org/new/en/education/themes/leading-the-international-agenda/right-to-education/>, retrieved: 2015-04-03). 